\title{
A New Alternative Technique for Denture Identification
}

\author{
${ }^{1}$ Ashish R Jain, ${ }^{2} \mathrm{P}$ Sindhu, ${ }^{3} \mathrm{CJ}$ Venkata Krishnan, ${ }^{4}$ Chitraa R Chandran
}

\begin{abstract}
Forensic science deals with examining and gathering information related to an accident or a crime scene. The contribution of prosthodontics to forensic odontology is highly significant after the invention of denture labeling techniques. Personal identification is inevitable in case of accident, loss of memory, state of unconsciousness and in hospitals. Labeled dentures can remarkably help identify the dead after disasters and accidents. Since then various denture markers were described in literature. This case report highlights an alternative technique of denture identification wherein a quick response code (QR Code) is incorporated into the processed denture using a clear acrylic sheet instead of self cure acrylic resin.
\end{abstract}

Keywords: Acrylic sheet, Barcode, Denture identification, Forensic, Scanning.

How to cite this article: Jain AR, Sindhu P, Krishnan CJV, Chandran CR. A New Alternative Technique for Denture Identification. World J Dent 2015;6(3):188-192.

Source of support: Nil

Conflict of interest: None

\section{INTRODUCTION}

Forensics was born when the body of Charles was identified in the battle of Nancy by the absence of a tooth in the lower arch. Later, in 1835, prosthetic importance in forensics came into picture when a burned body was identified by the gold denture of the victim. Identification of a dead or missing person is highly important in case of major disasters like earthquakes, fire, plane crashes, etc. Identification of the dead can be easily made with denture identification system. ${ }^{1}$

\footnotetext{
${ }^{1}$ Research Scholar, Senior Lecturer, ${ }^{2}$ Student (IIIrd Year) ${ }^{3}$ Research Scholar, Professor and Head, ${ }^{4}$ Professor and Head

${ }^{1}$ Department of Prosthodontics, Tagore Dental College and Hospital, Saveetha University, Chennai, Tamil Nadu, India

${ }^{2}$ Department of Prosthodontics, Tagore Dental College and Hospital, Chennai, Tamil Nadu, India

${ }^{3}$ Department of Prosthodontics, Tagore Dental College and Hospital, Bharath University, Chennai, Tamil Nadu, India

${ }^{4}$ Department of Periodontics, Tagore Dental College and Hospital, Chennai, Tamil Nadu, India

Corresponding Author: Ashish R Jain, Research Scholar, Senior Lecturer, Department of Prosthodontics, Tagore Dental College and Hospital, Saveetha University, Rathinamangalam, Vandalur Post Chennai-600127, Tamil Nadu, India, Phone: 09884233423 e-mail: dr.ashishjain_r@yahoo.com
}

A denture, like all personal items, can be lost or misplaced in a hospital or nursing home thus needs to be labeled for future identification. Identification is an essential requirement of any medicolegal investigation and positive identification through labeled dentures plays a key role in forensics. ${ }^{2}$ Thus, labeling dentures are totally necessary. Labeling of all dentures are recommended by most international dental associations and forensic odontologists. In fact, in some countries and certain states of the USA, the labeling of dentures is regulated by legislation. Certain ideal requisites of a denture marker are that it should be biologically inert, easy to apply, esthetically acceptable, etc. The two main methods in marking dentures are surface method and inclusion method. The surface method includes scribing and embossing technique. In inclusion method, the markers are enclosed in the denture. The various denture markers include quick response code (QR Code), denture bar coding, lenticular card, ID band, paper strip, T bar, laser etching, electronic microchips, photographic, radiofrequency identification (RFID) tags and subscriber identity module (SIM). ${ }^{1-3}$

\section{CONVENTIONAL QR CODE LABELING TECHNIQUE}

The QR Code is generated as mentioned in the subsequent paragraph and it is well protected with a cello tape or laminated. A slot is created on palate of a maxillary denture or lingual flange of a mandibular denture in accordance with the size of the QR Code generated. The QR Code is placed in the slot and auto polymerizing clear acrylic resin is placed over the barcode till the surface level of denture. Another method uses compression molding technique where a heat-cured clear acrylic resin is applied on surface of the mold and the laminated QR Code is applied in the inverted fashion. Over the QR Code, regular pink acrylic resin is applied and the denture is polymerized. Or a Putty (addition silicone) shaped into desired form can be placed into the tissue surface of the denture and flask is closed. Once the resin has reached rubbery stage, the flask is reopened and the putty removed. Then, the code can be placed in the cavity created and the rest of the cavity can be filled with the heat cured clear acrylic resin and polymerized. Another technique is where a cavity of desired shape is created in the polymerized denture. The code can then be placed 
in the cavity, filled with the heat cured clear acrylic resin and polymerized. . $^{3,4}$

The disadvantages of the above mentioned techniques are:

- Seepage of monomer in case of self-cure resin. The monomer smudges the QR Code in spite of lamination.

- Highly technique sensitive

- Possible distortion of barcode during heat curing cycle

- Development of air voids in the resin placed over the barcode (heat/self-cure resin)

- High expense in case of putty index technique.

This article describes a new technique of QR Code inclusion in removable dentures in comparison with the conventional method which encloses barcode in dentures using clear self/heat-cure acrylic resin.

\section{BARCODE}

A barcode is an optical machine-readable representation of data which can be read with a barcode scanner. Barcodes reveal a large amount of data about the patient compared to labels bearing just names and ID numbers. The barcode symbol represents general data, such as name, age, sex, address, occupation, phone number, and nationality of the patient. Quick response code is a twodimensional (2D) type of barcode. 5,6

\section{BARCODE SCANNER}

The barcode (QR Code) can be easily scanned and the patient data are revealed immediately within seconds. The barcode scanner application is easily downloaded from the web and installed in an android device or any smart phone. ${ }^{7,8}$

\section{METHOD OF USE}

- The patient information was entered in the QR Code generator software or website: https://www.theqrcode-generator.com/

- A QR Code was generated. Minimum available size of the QR Code was selected.

- The QR Code was printed in an A4 sheet and cut.

- The QR Code scanner application was downloaded in the android device or smart phone.

- The scanner application scanned the QR Code within seconds.

\section{CASE REPORT}

A 55 years old female patient reported to our hospital (Tagore Dental College and Hospital, Chennai, India) with a chief complaint of missing teeth. The patient had no relevant medical history. An intraoral examination revealed missing teeth in the maxilla and mandible. The following steps were taken to place a 'labeled' removable prosthesis and to restore the form, function and esthetics of the oral cavity.

- First, the patient was motivated regarding the use and importance of denture marking system.

- A primary impression of maxilla and mandible was made with alginate.

- The cast was poured and regular clinical and lab steps were followed and the denture is processed (Fig. 1).

- The patient detail obtained from the case history was converted to a QR Code as mentioned above (Fig. 2).

- The size of the QR Code was measured and a groove (1.5 mm depth) in accordance with the QR Code size was created on the palate/lingual flange of the denture without affecting its structure (Fig. 3).

- A clear 'Acrylic Sheet' of $1 \mathrm{~mm}$ thickness was taken and cut to the size of the QR Code (Fig. 4).

- The QR Code was placed on the groove created and the acrylic sheet was placed over it.

- The margins of the acrylic sheet were fused to the denture with the help of auto polymerizing acrylic resin.
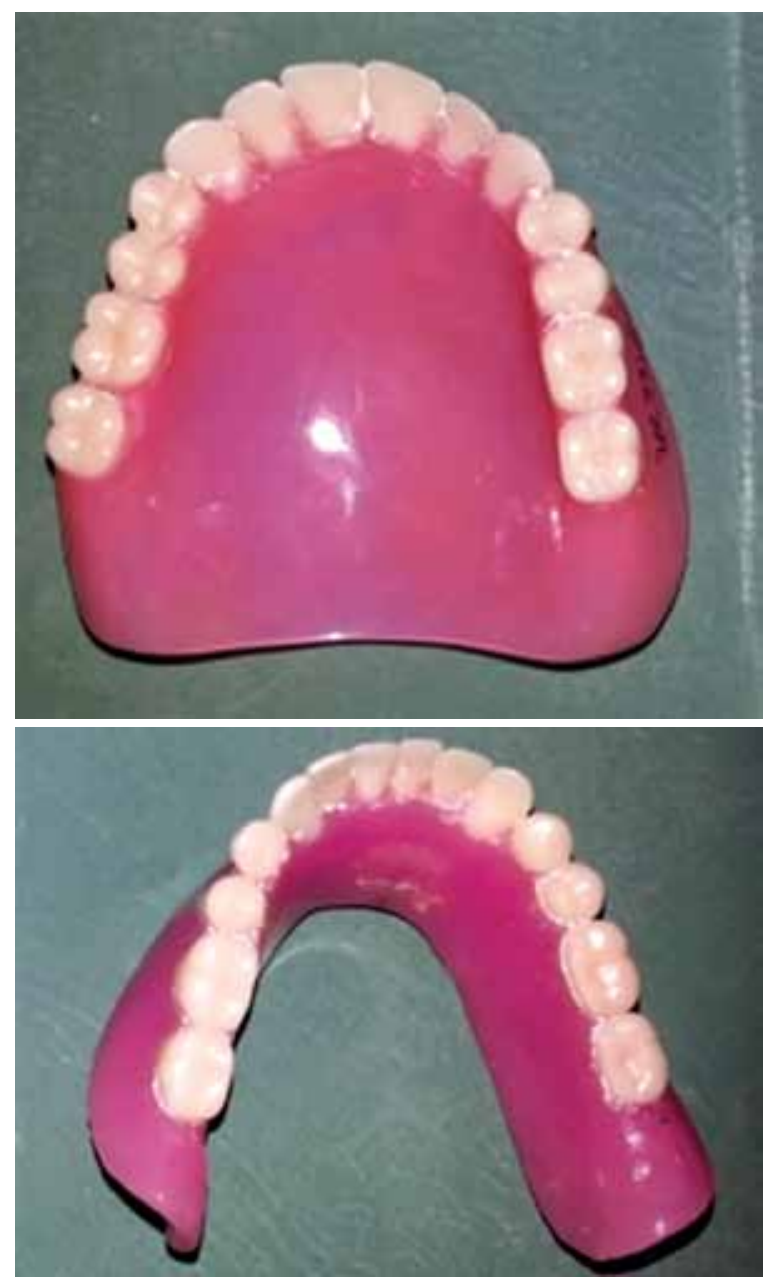

Fig. 1: Maxillary and mandibular complete denture 


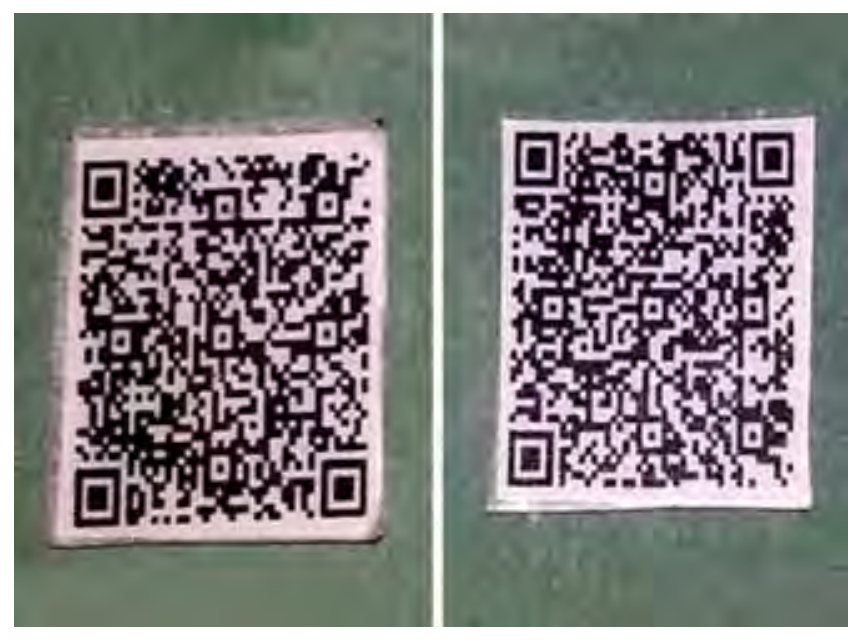

Fig. 2: Printed QR Code
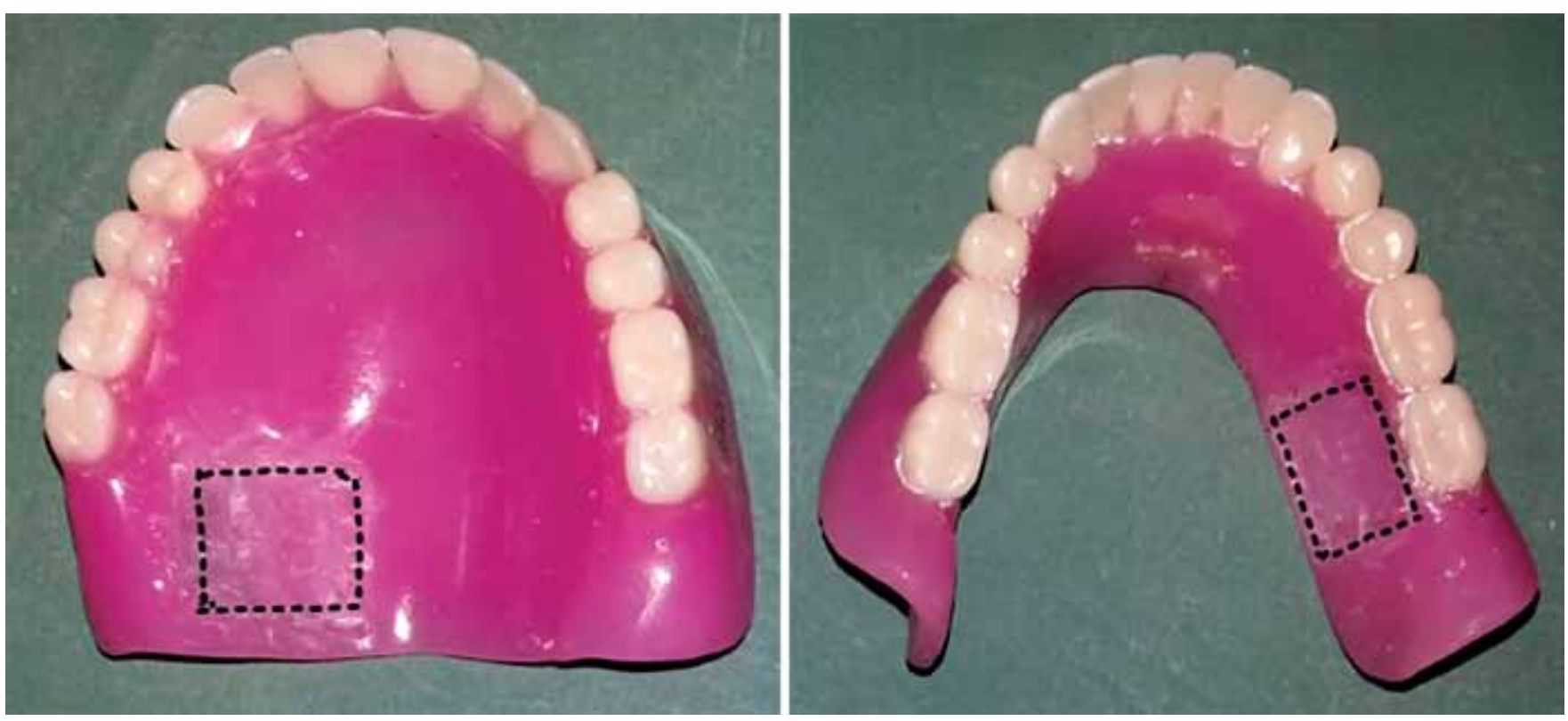

Fig. 3: Grooves created on palate of maxillary denture and lingual flange of mandibular denture
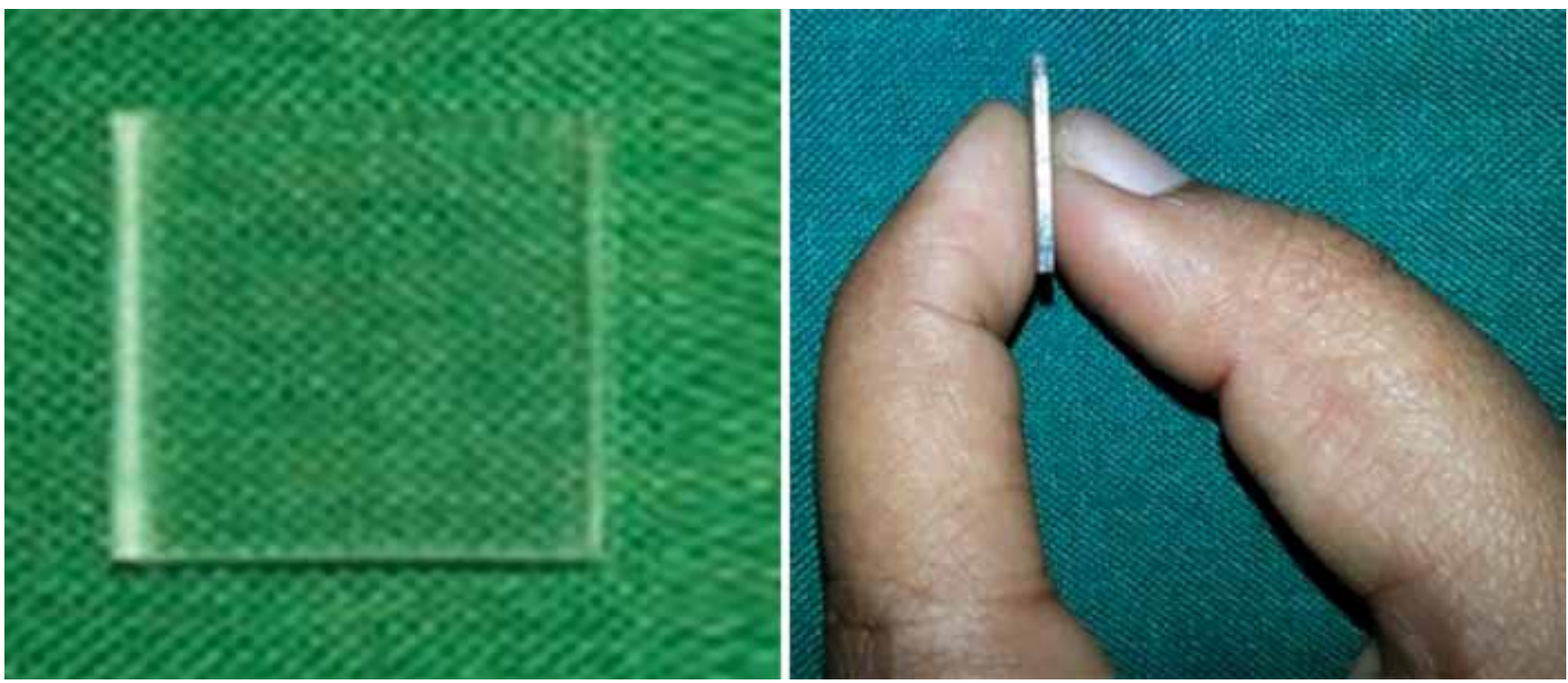

Fig. 4: Clear acrylic sheet of $1 \mathrm{~mm}$ thickness 

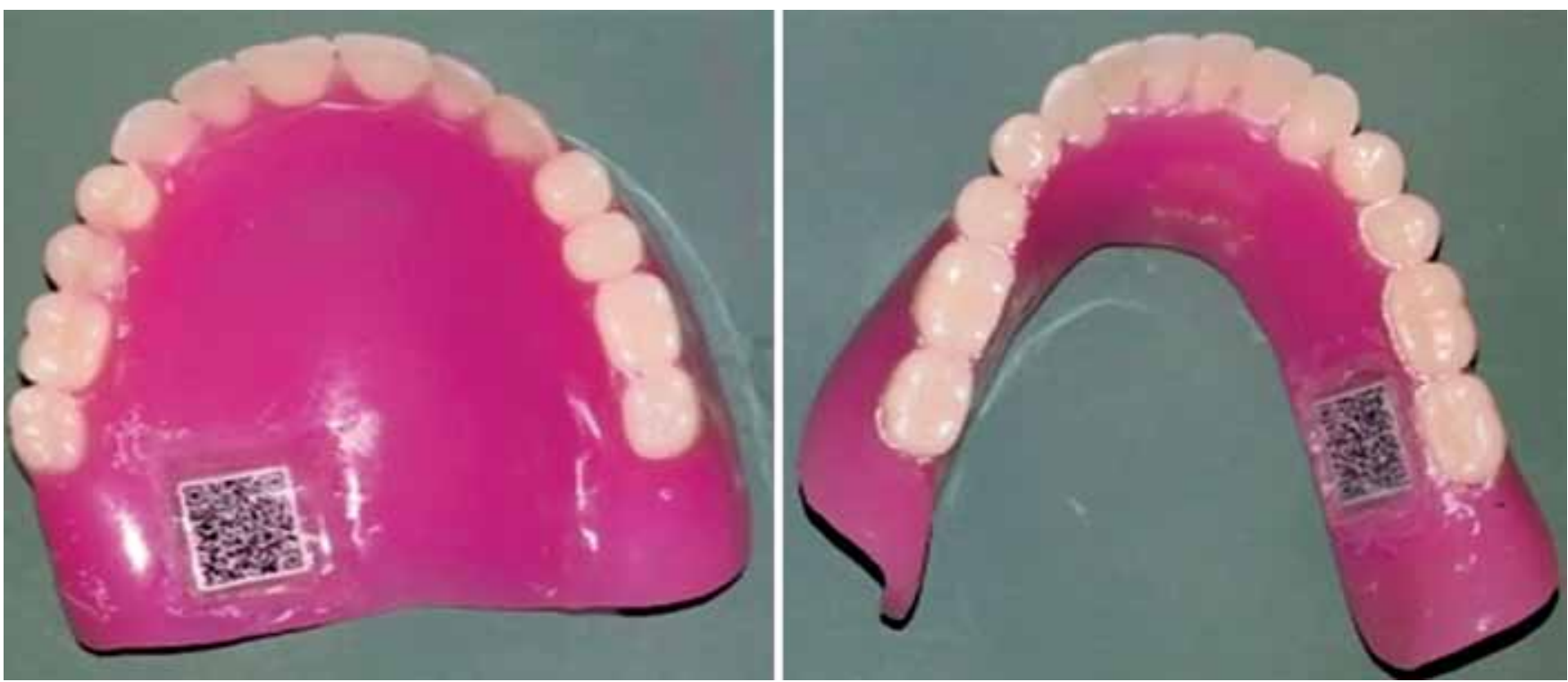

Fig. 5: Quick response code finished maxillary and mandibular denture
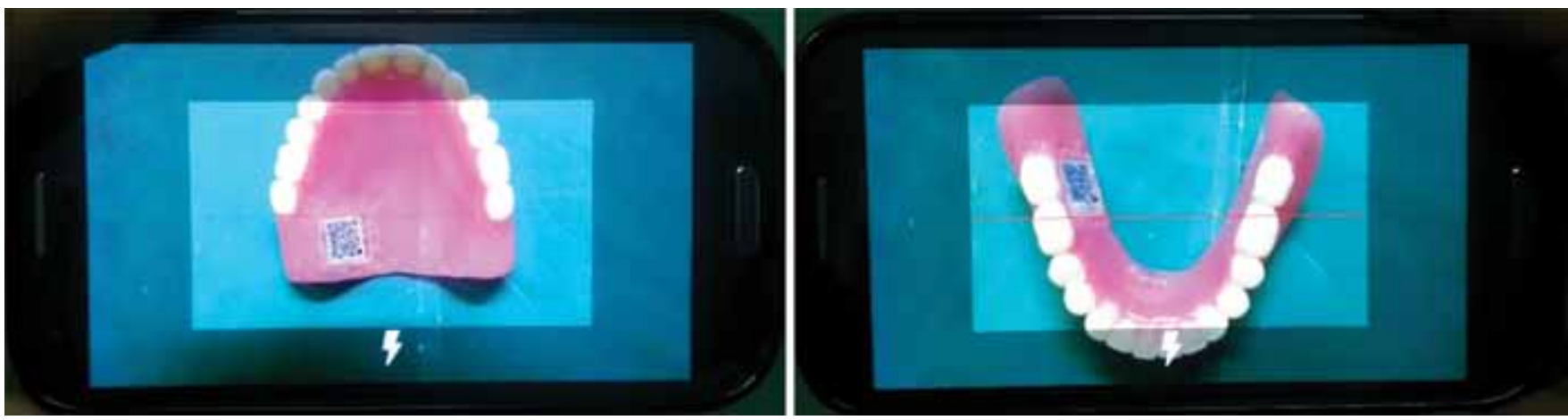

Fig. 6: Scanning the QR Code using smart phone
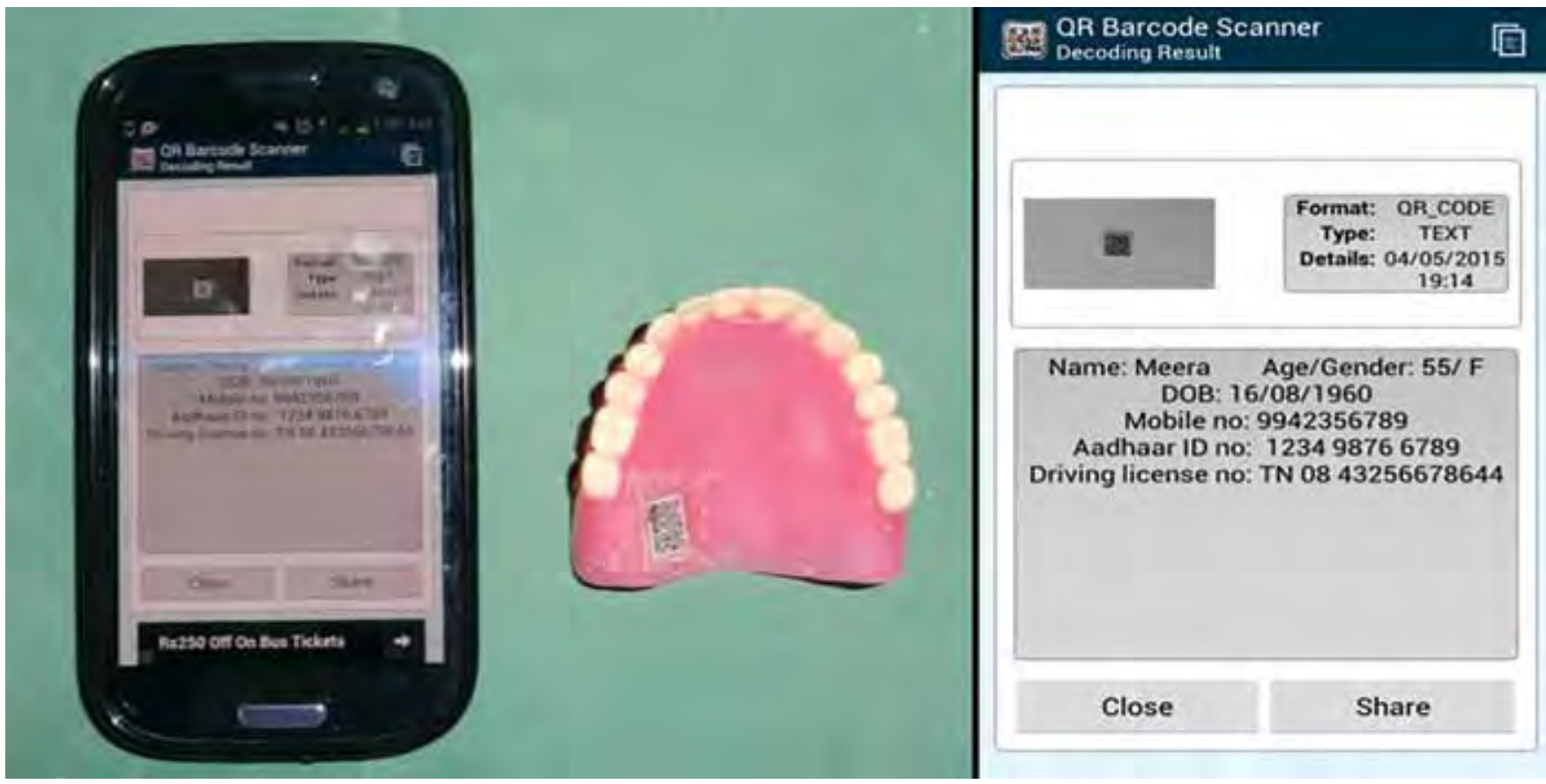

Name: Meera Age/Gender: $55 / \mathrm{F}$ DOB: $16 / 08 / 1960$

Mobile no: 9942356789

Aadhaar ID no: 123498766789

Driving license no: TN 0843256678644

Fig. 7: Quick response code deciphered 
- A trial was done by placing the acrylic sheet both in $40 \%$ sulfuric acid and $99 \%$ hydrochloric acid for three consecutive days and it was still effective upon scanning a QR Code.

\section{ADVANTAGES}

- No seepage of monomer into the QR Code

- Simple to construct

- No distortion or air voids over the QR Code

- Inexpensive

- Does not alter the structure, adaptation and esthetics of the denture

- Gives definite information.

\section{CONCLUSION}

Quick response code labeling is an effective method in denture identification system. The conventional method is technique sensitive and may cause distortion of barcode or affects the readability of $\mathrm{QR}$ Code. Transparent acrylic sheets are manufactured from $100 \%$ pure monomer with no air voids. They are easily available. In this case, the patient was satisfied with the removable denture in terms of comfort, function and esthetics. Patient experienced no inconvenience during a recall after 6 months. The acrylic sheet was not damaged by saliva or denture cleansing solution. It is the role of a dentist to motivate patients toward denture identification system.

\section{REFERENCES}

1. Ling BC. Computer-printer denture microlabeling system. J Prosthet Dent 1998;79:363-364.

2. Lamb DJ. A simple method for permanent identification of dentures. J Prosthet Dent 1992;67:894.

3. Coss P, Wolfaardt JF. Denture identification system. J Prosthet Dent 1995;74:551-552.

4. Berry FA, Logan GI, Plata R, Riegel R. A postfabrication technique for identification of prosthetic devices. J Prosthet Dent 1995;73:341-343.

5. Stevenson RB. Marking dentures for identification. J Prosthet Dent 1987;58:255.

6. Ryan LD, Keller JB, Rogers DE, Schaeffer L. Clear acrylic resin T-bar used in denture identification. J Prosthet Dent 1993;70:189-190.

7. Reeson MG. A simple and inexpensive inclusion technique for denture identification. J Prosthet Dent 2001;86:441-442.

8. Matsumura H, Shimoe S. Incorporation of a cast, embossed identification plate into a partial denture framework. J Prosthet Dent 2002;88:215-217. 